\title{
Compositional analysis of Chami cheese made from bovine milk in UAE
}

\author{
Aysha O. A. Al Katheeria, Bhawna Sobtia , Sami Ghnimi ${ }^{\mathrm{b}}$, Afaf Kamal-Eldin ${ }^{\mathrm{a}, *}$ \\ ${ }^{a}$ Department of Food, Nutrition, and Health, College of Food and Agriculture, United Arab Emirates University, Al Ain - 15551, UAE, ${ }^{b}$ University \\ of Lyon, Université Claude Bernard Lyon 1, CNRS, LAGEPP UMR 5007, 43 Bd 11 Novembre 1918, 69622 Villeurbanne, France
}

\section{A B S T R A C T}

Samples of nine home-made, commercial Chami cheese samples were analyzed for chemical composition, texture, and rheology. The samples showed large variations in moisture, protein, fat, ash, mineral contents, and pH values. Fat content, fatty acid composition, and differential scanning calorimetry analyses suggested addition of extra fat in some samples either butter or vegetable oil. The sodium content in the 9 cheese samples varied from $223-2411 \mathrm{mg} / \mathrm{kg}$ with three samples having very high contents 1756,2024 , and $2411 \mathrm{mg} / \mathrm{kg}$ indicative of added salt. The sample with the low moisture content $(60.9 \%)$ was the hardest among the cheeses. Rheological examination showed the Chami cheese samples of more elastic than viscous behavior.

Keywords: Chami; Cheese; Chemical Composition; Texture; Rheology

\section{INTRODUCTION}

Traditional foods represent an important part of the Emirati culture, identity, and heritage. The diet of Emirati citizens includes many imported foods but traditional foods that are either prepared at home or purchased from restaurants still contribute a significant proportion of the diet of the local people (Habib et al., 2011). However, production of almost all traditional cheeses occurs to meet the local demand and those cheeses are not very well known in other regions. One of the appreciated Emirati foods is Chami, which is a traditionally fermented white cheese characterized by weak gel structure resembling in freshness cottage cheese that has been drained (Nessrien, 2013) and similar to Petit Suisse cheese in consistency (Pereira, 2016). The soft cheese like Chami should not have moisture level more than 55\% whereas the milk fat should not be under the amount of $30 \%$. The fat is adjusted by adding salt and nitrogen which can improve its spreadability. The soft cheese can also contain gelling and emulsifying locust gum bean for the thickening mechanisms. It can contain fat like $30.3-33.6 \%$ whereas the desired amount of the protein can be $8-10 \%$. The soft cheese is hugely dependent on the lactate amount that needs to be $2-3 \%$ for perfect chemical bonding to procure consumable character (Kondyli et al.,
2012). Chami has an improved shelf life and sensory properties due to the development of characteristic sweet taste with slight acidic and diacetyl flavor (Nessrien et al., 2013). Chami cheese is consumed generally with other food item (rice, date fruit, bread) during breakfast or consumed in dried form as Kami or Igt. There are many traditional kinds of cheese like the Chami in different countries such as Feta, Karish, Jammed, Koumiss, Jaben, Amasi, and Wara cheeses.

Chami cheese is prepared at homes and is commercialized by women. The quality of the cheese is primarily determined by the level of freshness of the milk used and also by external processing factors such as exposure to heat, air, and light. The preparation method and storage may change the quality of the prepared cheese leading to degradation and/or formation of undesirable flavors and tastes (Claudia et al., 2015). The producers of Chami cheese usually develop their own recipes to ensure a good shelf-life and sensory quality with regard to texture and taste. Therefore, some variability of the composition and quality of the homeproduced Chami cheese is expected. There are not any studies reported on physico-chemical and compositional properties of chami cheese. Faced with extinction of some traditional cheeses and changes in milk production and

\footnotetext{
${ }^{*}$ Corresponding author:

Afaf Kamal-Eldin, Department of Food, Nutrition, and Health, College of Food \& Agriculture, United Arab Emirates University, Al Ain - 15551, UAE. E-mail: afaf.kamal@uaeu.ac.ae
} 
cheese manufacture, a real need exists for the knowledge of characterization of texture and fat profile of traditional cheeses. Therefore, this study aimed to analyze commercial Chami samples and evaluate the variability in their chemical, textural, and rheological properties.

\section{MATERIAL AND METHODS}

\section{Chami cheese samples and chemicals}

Nine different commercial Chami samples procured from Abu Dhabi, Al Ain, Sharjah, and Fujairah were used in this study. Fig. 1 shows the photograph and procedure for preparation of chami cheese. The samples were immediately analyzed for texture and rheology and were frozen at $-20^{\circ} \mathrm{C}$ for the other analyses. Boron trifluoride for fatty acid methylation, fatty acid standards for gas chromatography analysis, potassium hydroxide for saponification, sodium hydroxide and phenolphthalein for titration, and all other reagents of analytical grade were purchased from Sigma (St Louis, CA, USA).

\section{Physicochemical analysis}

Chami cheese samples were homogenized in a mortar and pestle and analyzed for their proximate composition (fat content, total protein content, moisture and ash) using reference methods (AOAC, 2000). The pH of homogenized Chami samples was measured using $\mathrm{pH}$ meter (OHAUS Model ${ }^{\circledR}$ Starter 3100, Cole-Parmer Canada, Montreal, Canada).

Mineral analysis was performed using the inductively coupled optical emission spectrometer that runs axial and radial view analysis (ICP-OES model 710-Es, Varian/ Agilent, Santa Clara, CA, USA). A microwave accelerated reaction system (model Mars 5, CEM Corporation, Matthews, North Carolina, USA) was used to digest the samples by adding $10 \mathrm{ml}$ of concentration nitric acid (70\% $\mathrm{HNO}_{3}$ ) and $2 \mathrm{ml}$ hydrochloric acid $(37 \% \mathrm{HCl})$ in a closed vessel. Once dissolved, the solutions could cool and made up to $50 \mathrm{ml}$ in a volumetric flask. After cooling, the vessel contents were filtered before analysis by ICP-OES.

For the analysis of fatty acid composition, fatty acid methyl esters (FAME) were prepared by saponifying samples of the fat $(10 \mathrm{mg})$ with $0.5 \mathrm{~N}$ alcoholic potassium hydroxide $(1 \mathrm{ml})$ in sealed vials at $100^{\circ} \mathrm{C}$ for 10 minutes, cooling, and methylation with $\mathrm{BF}_{3}$ reagent $(2 \mathrm{ml})$ by heating again at $100^{\circ} \mathrm{C}$ for $10-15$ minutes. The FAMEs

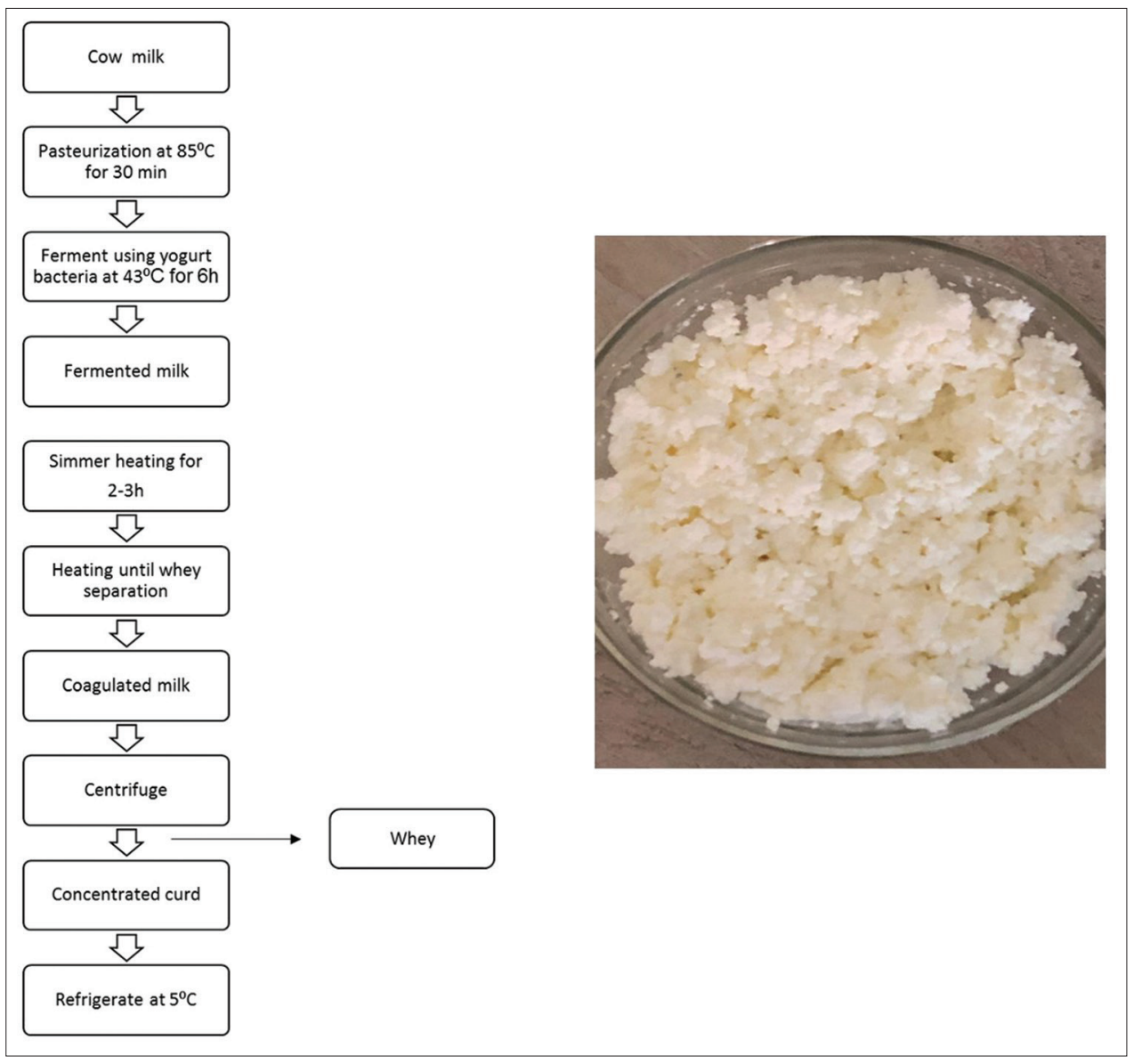

Fig 1. General procedure and photograph of Chami from cow milk. 
were extracted twice in heptane $(1 \mathrm{ml})$ and the extract was washed twice with water $(1 \mathrm{ml})$ and dried using anhydrous $\mathrm{Na}_{2} \mathrm{SO}_{4}$. The extract was concentrated to 0.5 $\mathrm{ml}$ and transferred to a clean GC vial for injection into the gas chromatograph (6500GC System, YL instrument, Anyang, South Korea). The injected volume was $1 \mu \mathrm{l}$, and the injector was set at $240^{\circ} \mathrm{C}$ in a split mode $(1: 10)$. Separations were performed on CP 7488 Varian capillary column (50 m, $0.25 \mathrm{~mm}$ i.d., $0.2 \mu \mathrm{m}$ film thickness, USA) programmed as follows: $80^{\circ} \mathrm{C}(2 \mathrm{~min}), 5^{\circ} \mathrm{C} / \mathrm{min}, 190^{\circ} \mathrm{C}$ $(5 \mathrm{~min}), 2^{\circ} \mathrm{C} / \mathrm{min}, 210^{\circ} \mathrm{C}(5 \mathrm{~min}), 10^{\circ} \mathrm{C} / \mathrm{min}$, and $240^{\circ} \mathrm{C}$ (5 min). Helium was used as a carrier gas at a flow rate of $1.5 \mathrm{ml} / \mathrm{min}$. Peaks were detected using flame ionization detector set at $300{ }^{\circ} \mathrm{C}$.

\section{Differential scanning calorimetry (DSC)}

The glass-transition temperature $\left(\mathrm{T}_{\mathrm{g}}\right)$ and thermal behavior of homogenized Chami samples were measured using differential scanning calorimetry (TA Instruments Q100, New Castle, UK). A heat-cool-heat temperature programming protocol was adopted with the first heating at $5{ }^{\circ} \mathrm{C} / \mathrm{min}$ followed by cooling at $-30^{\circ} \mathrm{C} / \mathrm{min}$ and final heating at $5^{\circ} \mathrm{C} / \mathrm{min}$ to $70^{\circ} \mathrm{C}$ as the expected thermal events (glass transition temperature and a melting point of fat lie within this range temperature (Hjalmarsson, 2015).

\section{Texture profile analysis}

Instrumental texture profile analysis (TPA) parameters were determined using a Brookfield Texture Analyzer CT3 (Middleboro, MA, USA) utilizing two cycles of compressiondecompression. The load cell of measurement was up to $50 \mathrm{~kg}$ weight. The Chami sample was filled in cup size $25 \mathrm{~g}$. The instrument was set to zero before each measurement and compression mode was used for the textural analysis. The TPA parameters were determined from force-time curves depending on the following attributes: peak force of the first compression cycle $1(\mathrm{~N})$; peak force of the second compression cycle $2(\mathrm{~N})$; adhesive forces; resilience, springiness, fracturability $(\mathrm{N})$, cohesiveness, chewiness, and gumminess (Hjalmarsson, 2015).

\section{Rheological properties}

Rheological measurements were performed using a DHR-2 hybrid rheometer (TA Instruments Ltd., Discovery, New Castle, DE, USA). A representative portion of each sample was carefully removed and put on the bottom plate of the rheometer. The top plate was slowly down until space was 1 $\mathrm{mm}$ and excess sample was removed from the edges of the plate. The oscillatory trails frequency sweep test was carried out with a frequency ranging between 0.01 and $10 \mathrm{~Hz}$, at the same deformation $(1 \%)$ within a linear viscoelastic region of less than $2 \%$. The storage modulus $\left(G^{\prime}\right)$ and the loss modulus $\left(G^{\prime \prime}\right)$ were recorded as a function of frequency. The temperature was set at $10{ }^{\circ} \mathrm{C}$ during the tests. The tan delta were calculated by taking the ratio between $G^{\prime \prime}$ and $\mathrm{G}^{\prime}$ (Bayarri et al., 2009).

\section{Statistical analysis}

All the experiments were independently performed two to three times. All data were expressed as a mean value. The differences in physicochemical properties of commercial Chami samples were analyzed using one-way ANOVA test.

\section{RESULTS AND DISCUSSIONS}

\section{Physicochemical parameters}

Values of moisture, protein, fat, ash, $\mathrm{pH}$ of nine homemade Chami ranged between 60.9-84.1\%, 8.2-14.6\%, 0.5-7.8\%, 5.1-8.0\%, respectively, as shown in Table 1 . The moisture values are comparable to other traditional soft cheeses like feta cheese having moisture contents of $60 \%$ and cottage cheese having about $80 \%$ moisture (Nessrien et al., 2013). In addition, protein values were in accordance with Dhuol et al. (2013) and Kondyli et al. (2012) who reported 11.2$21.4 \%$ protein in soft cheeses and the fat content was reported as $0.4-5.3 \%$ in cottage cheese by Nessrien et al. (2013). The ash content was also comparable to other soft cheeses, for example cream cheese $(7 \%)$ (Nessrienet al., 2013) and cottage cheese (8.0\%) (Nessrien et al., 2013). The $\mathrm{pH}$ of Chami cheese samples were in the similar range of 4.2-4.5 as reported by Benkerroum and Tamime (2004).

The DSC thermograms show differences in the sizes of their fat melting peaks of three Chami samples (2, 5 and 9), as presented in Fig. 2,. These Chami samples showed a distinctive peak at $\left(0^{\circ} \mathrm{C}\right)$ which represents the melting point of ice water in the samples. The two samples showed characteristic peaks that can be associated with the melting temperature of fat. However, it can be noticed the peak sizes in sample 5 is relatively

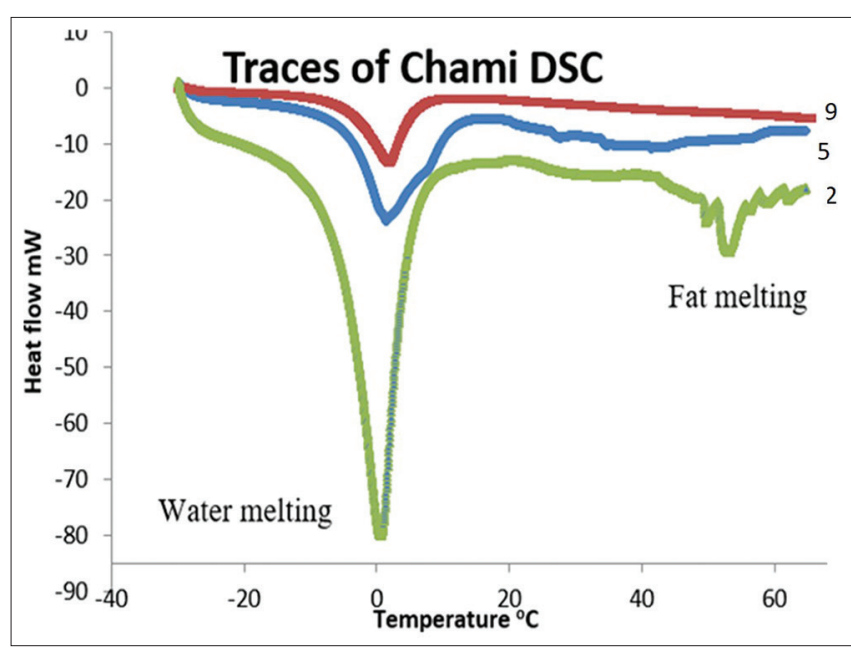

Fig 2. Differential scanning calorimetry (DSC) of Chami samples: red (samples 9), blue (sample 6), and green (sample 2). 
Katheeri, et al.

Table 1: Proximate and mineral composition of the studied Chami cheese samples

\begin{tabular}{|c|c|c|c|c|c|c|c|c|c|c|c|c|c|}
\hline \multirow[t]{2}{*}{ Sample } & \multicolumn{4}{|c|}{ Proximate components (\%) } & \multirow[t]{2}{*}{$\mathrm{pH}$} & \multicolumn{8}{|c|}{ Minerals (mg/Kg) } \\
\hline & Moisture & Protein & Fat & Ash & & $\mathrm{Na}$ & $\mathbf{K}$ & $\mathrm{Ca}$ & $\mathrm{Mg}$ & $\mathrm{Fe}$ & $\mathrm{Zn}$ & $\mathbf{P}$ & $\mathrm{S}$ \\
\hline 1 & 83.3 & 8.5 & 1.0 & 5.2 & 4.3 & 389 & 1008 & 1213 & 100 & 2 & 5 & 1530 & 1081 \\
\hline 2 & 60.9 & 14.6 & 7.8 & 6.7 & 4.3 & 2411 & 988 & 944 & 86 & 2 & 1.8 & 1603 & 1291 \\
\hline 3 & 81.1 & 10.0 & 0.8 & 6.6 & 4.0 & 668 & 864 & 1218 & 94 & 2 & 5 & 1426 & 910 \\
\hline 4 & 81.7 & 8.2 & 1.0 & 6.5 & 3.7 & 223 & 695 & 812 & 76 & 2 & 7 & 1297 & 1009 \\
\hline 5 & 72.8 & 12.5 & 2.1 & 8.0 & 4.5 & 263 & 816 & 959 & 87 & 1 & 7 & 1578 & 1214 \\
\hline 6 & 80.9 & 11.3 & 1.0 & 5.1 & 3.6 & 2024 & 671 & 970 & 92 & 2 & 5 & 2018 & 1437 \\
\hline 7 & 79.3 & 7.5 & 6.8 & 3.4 & 4.1 & 385 & 833 & 833 & 84 & 2 & 4 & 985 & 541 \\
\hline 8 & 76.9 & 12.7 & 0.5 & 7.2 & 4.0 & 1756 & 736 & 736 & 83 & 1 & 4 & 1096 & 604 \\
\hline 9 & 84.1 & 8.9 & 0.5 & 5.2 & 4.4 & 234 & 736 & 736 & 83 & 2 & 9 & 1481 & 1175 \\
\hline Range & $60.9-84.1$ & $8.2-14.6$ & $0.5-7.8$ & $5.1-8.0$ & $3.6-4.5$ & $223-2411$ & $736-1008$ & $736-1218$ & $76-100$ & $1-2$ & $1.8-9$ & $985-2018$ & $541-1291$ \\
\hline Mean & 77.8 & 10.4 & 2.4 & 6.0 & 4.1 & 928 & 816 & 936 & 87.2 & 1.8 & 5.3 & 1446 & 1029 \\
\hline SD & 7.2 & 2.4 & 2.8 & 1.4 & 0.3 & 877 & 121 & 182 & 7.1 & 0.4 & 2.1 & 303 & 301 \\
\hline
\end{tabular}

smaller than the peaks of sample 2. This revelation agrees with the findings in the proximate composition analysis which showed that no. Sample 5 contained 2.1 $\%$ of fat while the sample 2 had $7.8 \%$ of fat (Table 1 ). In addition, the fat in sample 2 Chami melts at high temperatures of $45^{\circ} \mathrm{C}$ and $50^{\circ} \mathrm{C}$ for different fractions while sample 5 and 9 sample had low melting temperature of the fat i.e. between $25^{\circ} \mathrm{C}$ and $38^{\circ} \mathrm{C}$. Although, there was no difference between the three cheese samples in the fatty acid composition (Table 2) suggesting that the difference in DSC results was mainly due to differences in total milk fat content, i.e. in the use of skimmed versus whole fat milk.

Table 1 shows the average values $(\mathrm{mg} / \mathrm{kg}$ ) of different minerals namely calcium $(\mathrm{Ca})$, potassium $(\mathrm{K})$, magnesium $(\mathrm{Mg})$, sodium $(\mathrm{Na})$, phosphorous $(\mathrm{P})$, sulfur $(\mathrm{S})$, iron $(\mathrm{Fe})$, manganese $(\mathrm{Mn})$, and zinc $(\mathrm{Zn})$. The sodium content in the 9 cheese samples varied from 223-2411 ppm with three samples having very high contents: (1756), (2024), (2410) suggesting addition of salt while preparing these cheese samples to influence taste, texture, and shelf-life of the cheese. Moreover, Dhuol and Hamid (2014) reported similar values for sodium $(\mathrm{Na})$ and potassium $(\mathrm{K})$ contents in case of soft white cheese. In addition, the $\mathrm{pH}$ values also impact the mineral content as it causes the movement of minerals from center to the external layer of cheese block or vice-versa (Kwak, 2011).

\section{Texture profile analysis (TPA)}

Results of TPA of nine Chami samples are given in Table 3. Sample 2 reported highest hardness cycles 1 and 2 , fracturability, gumminess, and chewiness values while sample 4 had the least. The low hardness values in samples $1,3,4,6,7,8,9$ can be explained by their higher moisture contents in these compared to other samples (Table 1). Hardness cycles 1 is positively correlated to hardness cycle 2, fracturability, gumminess, and chewiness but
Table 2: Fatty acids composition of three selected Chami cheeses (relative \%)

\begin{tabular}{lccc}
\hline Fatty acids & \multicolumn{3}{c}{ Cheese Sample Number } \\
\cline { 2 - 4 } & $\mathbf{2}$ & $\mathbf{5}$ & $\mathbf{9}$ \\
\hline C6:0 & 0.8 & 0.1 & 0.2 \\
C8:0 & 0.7 & 0.9 & 0.1 \\
C10:0 & 1.9 & 2.1 & 2.0 \\
C12:0 & 2.5 & 2.7 & 2.9 \\
C14:0 & 10 & 9.4 & 10 \\
C14:1 & 0.9 & 0.7 & 0.5 \\
C15:0 & 1.1 & 1.0 & 1.1 \\
C16:0 & 35.1 & 34.5 & 36.2 \\
C16:1 & 2.0 & 1.5 & 1.3 \\
C17:0 & 0.8 & 0.9 & 0.5 \\
C18:0 & 10.3 & 10.6 & 10.1 \\
C18:1 & 23.2 & 24.7 & 24.6 \\
C18:2 & 8.0 & 8.0 & 5.6 \\
C20:0 & 0.6 & 0.5 & 0.3 \\
C18:3 & 0.5 & 0.2 & 0.3 \\
C21:0 & N.D. & 0.3 & 0.9 \\
Others & 2.5 & 3.0 & 2.8 \\
\hline
\end{tabular}

N.D. $=$ Not detected

negatively correlated with springiness $(\mathrm{P}<0.05)$ (Table 4). The suitable chewiness provides a rich mouthfeel and enhances the joy of tasting cheese (Zheng, 2016). Textural attributes such as hardness, chewiness, gumminess are also positively influenced by protein content (Simoes et al., 2013) and fat content (Brighenti et al., 2008). Higher adhesiveness in samples 1,3 and 4 can be explained by their higher fat content, which softens the cheese. Adhesiveness can be explained as the work required to pull cheeses away from the surfaces and higher adhesiveness values may be attributed to interactions between protein and water (Pastorino et al., 2003). No differences were found in resilience and cohesiveness of the nine Chami samples. Fat content, especially saturated fatty acids, negatively correlate with resilience because the presence of fat in cheese leads to deformation of the product and reduction of its resilience. In addition, high $\mathrm{NaCl}$ content 
Table 3: Texture parameters of Chami samples

\begin{tabular}{|c|c|c|c|c|c|c|c|c|c|}
\hline Sample & $\begin{array}{l}\text { Hardness } \\
\text { Cycle } 1 \text { (g) }\end{array}$ & $\begin{array}{l}\text { Adhesiveness } \\
\text { (mJ) }\end{array}$ & Resilience & $\begin{array}{l}\text { Fracturability } \\
\text { (g) }\end{array}$ & $\begin{array}{l}\text { Hardness } \\
\text { Cycle } 2 \text { (g) }\end{array}$ & Cohesiveness & Springiness & $\begin{array}{c}\text { Gumminess } \\
\text { (g) }\end{array}$ & $\begin{array}{c}\text { Chewiness } \\
(\mathrm{mJ})\end{array}$ \\
\hline 1 & 328 & 3.2 & 0.1 & 245 & 215 & 0.4 & 8.1 & 142 & 11.8 \\
\hline 2 & 777 & 0.1 & 0.2 & 777 & 683 & 0.5 & 5.9 & 420 & 25.0 \\
\hline 3 & 423 & 1.8 & 0.1 & 391 & 174 & 0.5 & 5.1 & 193 & 12.1 \\
\hline 4 & 133 & 0.9 & 0.1 & 33 & 117 & 0.6 & 7.4 & 77 & 5.7 \\
\hline 5 & 632 & 0.1 & 0.3 & 632 & 572 & 0.6 & 6.3 & 383 & 25.0 \\
\hline 6 & 409 & 0.1 & 0.2 & 340 & 368 & 0.6 & 6.5 & 246 & 16.0 \\
\hline 7 & 510 & 0.3 & 0.2 & 438 & 466 & 0.6 & 6.3 & 304 & 18.8 \\
\hline 8 & 373 & 0.1 & 0.3 & 305 & 341 & 0.6 & 6.4 & 229 & 14.4 \\
\hline 9 & 458 & 0.1 & 0.2 & 458 & 407 & 0.5 & 4.1 & 220 & 12.0 \\
\hline Range & $133-777$ & $0.1-3.2$ & $0.1-0.3$ & $33-777$ & $117-683$ & $0.4-0.6$ & $4.1-8.1$ & $77-420$ & $5.7-25.0$ \\
\hline Mean & 449 & 0.74 & 0.18 & 402 & 371 & 0.5 & 6.2 & 246 & 15.6 \\
\hline $\mathrm{SD}$ & 183 & 1.1 & 0.08 & 216 & 186 & 0.07 & 1.2 & 109 & 6.4 \\
\hline
\end{tabular}

Table 4 : Pearson's correlation analysis of texture profile of Chami samples

\begin{tabular}{|c|c|c|c|c|c|c|c|c|c|}
\hline Variables & $\begin{array}{c}\text { Hardness } \\
\text { Cycle } 1\end{array}$ & Adhesiveness & Resilience & Fracturability & $\begin{array}{c}\text { Hardness } \\
\text { Cycle } 2\end{array}$ & Cohesiveness & Springiness & Gumminess & Chewiness \\
\hline $\begin{array}{l}\text { Hardness } \\
\text { Cycle } 1\end{array}$ & 1 & & & & & & & & \\
\hline Adhesiveness & -0.364 & 1 & & & & & & & \\
\hline Resilience & 0.411 & -0.881 & 1 & & & & & & \\
\hline Fracturability & 0.996 & -0.380 & 0.423 & 1 & & & & & \\
\hline $\begin{array}{l}\text { Hardness } \\
\text { Cycle } 2\end{array}$ & 0.970 & -0.505 & 0.541 & 0.963 & 1 & & & & \\
\hline Cohesiveness & -0.213 & -0.578 & 0.594 & -0.237 & -0.055 & 1 & & & \\
\hline Springiness & -0.638 & 0.514 & -0.370 & -0.674 & -0.563 & 0.266 & 1 & & \\
\hline Gumminess & 0.981 & -0.484 & 0.555 & 0.975 & 0.983 & -0.031 & -0.594 & 1 & \\
\hline Chewiness & 0.968 & -0.412 & 0.530 & 0.958 & 0.968 & -0.019 & -0.504 & 0.991 & 1 \\
\hline
\end{tabular}

increases the possibility of $\mathrm{Ca}^{2+}$ replacement and reduces the firmness and resilience of cheese. Cohesiveness showed a weak negative correlation with gumminess and chewiness attributes in agreement with previous findings (Zheng, 2016).

Principal component analysis of the texture profile of Chami cheese shows that two principal components (PCs) explained $88.7 \%$ of the variation in texture parameters; PC1 (65.8\%), and PC2 (22.9\%) (Fig. 3). Hardness cycles 1 and 2, cohesiveness, chewiness, fracturability, and resilience were separated from adhesiveness and springiness along PC1 while PC2 separates cohesiveness, resilience, and springiness from the rest of the parameters. The 9 samples showed variation in texture descriptors with samples showing cohesiveness/resilience (samples 5 and 7), hardness, chewiness, gumminess, and fracturability (samples 2), adhesiveness (samples 1, 3, and 9), or springiness (samples 4, 6, 8).

\section{Rheological analysis}

The rheological analysis was performed to assess the viscoelastic properties of Chami samples (Table 5). Frequency sweep test was conducted from 0.01 to

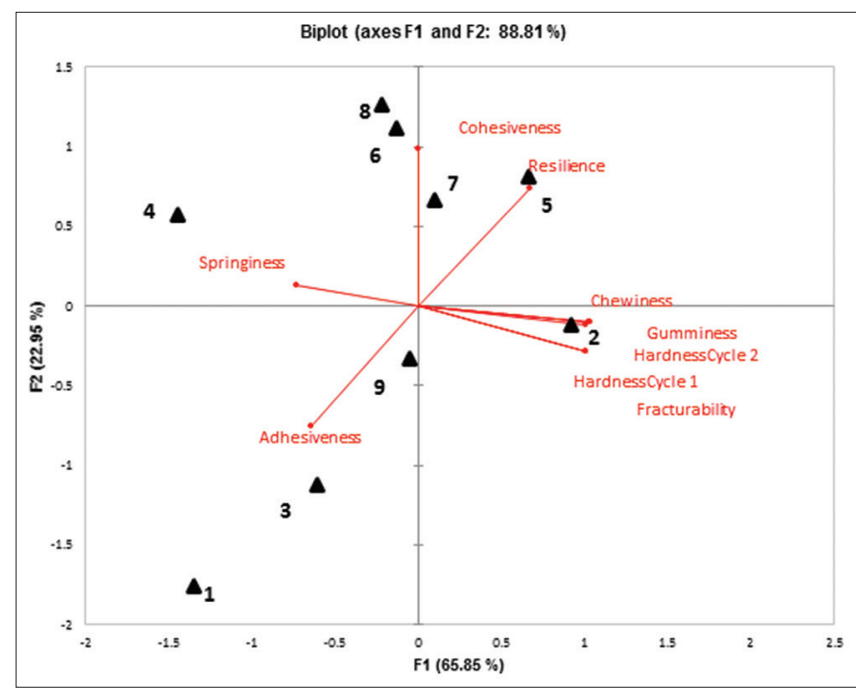

Fig 3. Principle component analysis of Chami cheese texture.

$10 \mathrm{~Hz}$ at a fixed strain of $1 \%$. The values of storage modulus (elastic; $G^{\prime}$ ), loss modulus (viscous; $G^{\prime \prime}$ ), apparent viscosity $(\eta)$, and tan delta $(\delta)$ were in range of 33-300 KPa, 8.5-100 KPa, 5-55 Pa.s and 0.22-0.30, respectively. The Elastic Modulus $G^{\prime}$ was higher than loss modulus $G^{\prime \prime}$ for all Chami samples implying that all Chami samples had more elastic structure than viscous. 
Table 5: Viscoelastic properties of Chami at a fixed frequency of $1 \mathrm{~Hz}$

\begin{tabular}{lcccc}
\hline Chami & $\begin{array}{c}\text { Elastic } \\
\text { modulus } \\
\mathbf{G \times}(\mathbf{k P a})\end{array}$ & $\begin{array}{c}\text { Viscous } \\
\text { modulus } \\
\mathbf{G \times \times}(\mathbf{k P a})\end{array}$ & $\begin{array}{c}\text { Apparent } \\
\text { viscosity } \\
\boldsymbol{\eta}(\mathbf{k P a} . \mathbf{s})\end{array}$ & $\begin{array}{c}\text { tan } \\
\text { delta }(\delta)\end{array}$ \\
\hline 1 & 40 & 9.7 & 5 & 0.24 \\
2 & 300 & 90 & 40 & 0.3 \\
3 & 100 & 30 & 19 & 0.3 \\
4 & 33 & 8.5 & 7 & 0.25 \\
5 & 300 & 100 & 51 & 0.3 \\
6 & 89 & 20 & 15 & 0.22 \\
7 & 250 & 71 & 40 & 0.28 \\
8 & 250 & 60 & 30 & 0.24 \\
9 & 301 & 101 & 55 & 0.3 \\
Range & $33-300$ & $8.5-100$ & $5-55$ & $0.22-0.30$ \\
Mean & 185 & 54.4 & 29.1 & 0.27 \\
SD & 117 & 38.2 & 18.6 & 0.03 \\
\hline
\end{tabular}

Viscoelasticity is the main feature for cheese structure (Lucey et al., 2003). The predominance of caseins in cheese matrix and cross-linkages between cheese proteins may be attributed to the elastic properties of cheese structure (Hassan et al., 2005). These results are in accordance with those reported by Ma et al. (1997) and Raphaelides et al. (2006). The tan delta is a measure that relates the viscous and elastic properties of a viscoelastic material (Bayarri et al., 2009). Since, tan delta values of all Chami cheeses are less than 1 indicating elastic behavior (solid-like) of the cheeses.

\section{CONCLUSIONS}

Chami is a traditional fermented soft cheese product in UAE, prepared by whey separation by either centrifuging or shaking, boiling, and dictation followed by final concentration of curd by sieving over a cloth. Nine Chami cheeses studied had comparable chemical compositions except for 3 samples found with high salt and 2 samples with high fat contents. Strong positive correlations were observed between hardness cycle 1 with hardness cycle 2, fracturability, gumminess, and chewiness but negatively correlations with springiness. The PCA showed that there is variation in texture descriptors with some samples showing cohesiveness/resilience (samples 5 and 7), hardness, chewiness, gumminess, and fracturability (2), adhesiveness (samples 1, 3, and 9), and springiness (sample 4, 6, 8). In addition, rheological studies showed that all Chami samples had more elastic structure than viscous.

\section{Authors' Contributions}

Aysha O. A. Al Katheeri: Investigation; Bhawna Sobti: Writing-Manuscript Draft, Sami Ghnimi: Supervision, Reviewing and Editing Manuscript Afaf Kamal-Eldina: Supervision, Reviewing and Editing Manuscript

\section{REFERENCES}

AOAC. 2000. Official Methods of Analysis. $17^{\text {th }}$ ed. Association of Official Analytical Chemists, Gaithersburg, MD, USA.

Bayarri, S., L. Gonzalez-Tomas and E. Costell. 2009. Viscoelastic properties of aqueous and milk systems with carboxymethyl cellulose. Food Hydrocoll. 23: 441-450.

Benkerrouma, N. and A. Y. Tamime. 2004. Technology transfer of some Moroccan traditional dairy products (Lben, Jben and Smen) to small industrial scale. Food Microbiol. 21: 399-413.

Brighenti, M., S. Govindasamy-Lucey, K. Lim, K. Nelson, and J. A. Lucey. 2008. Characterization of the rheological, textural, and sensory properties of samples of commercial US cream cheese with different fat contents. J. Dairy Sci. 91: 4501-4517.

Asensioa, C. M., R. Nelson, H. Grossob, H. R. Juliania. 2015. Quality preservation of organic cottage cheese using oregano essential oils. LWT Food Sci. Technol. 60: 664-671.

Dhuol, K. R. R. and O. I. A. Hamid. 2014. Vitamin C and minerals content of sudanese white soft cheese made from different levels of cassava powder (manitoh esculent). Am. J. Res. Commun. 2: 108-117.

Habib, H. M., H. I. Ali, W. H. Ibrahim and H. S. Afifi. 2011. Nutritional value of 10 traditional dishes of the United Arab Emirates. Ecol. Food Nutr. 50: 526-538.

Hassan, A. N., S. Awad and K. Muthukumarappan. 2005. Effects of exopolysaccharide-producing cultures on the viscoelastic properties of reduced-fat cheddar cheese. J Dairy Sci. 88: 4221-4227.

Hjalmarsson, M. 2015. The Effect of Vegetable Fat on Cheese Yield and Cheese Properties. $2^{\text {nd }}$ ed. SLU, Department of Food Science, Uppsala.

Kondyli, E., E. C. Pappa and A. M. Vlachou. 2012. Effect of package type on the composition and volatile compounds of Feta cheese. Small Rumin. Res. 108: 95-101.

Kwak, H. S., P. Ganesan and H. Y. Hong. 2011. Nutritional Benefits in Cheese In: D. F. Richard D (Ed.), Cheese: Types, Nutrition and Consumption. Nova Science Publishers Inc., New York, pp. 269-289.

Lucey, J., M. Johnson and D. Horne. 2003. Invited review: Perspectives on the basis of the rheology and texture properties of cheese. J. Dairy Sci. 86: 2725-2743.

Ma, L., M. A. Drake, G. V. Barbosa-Canovas and B. G. Swanson. 1997. Rheology of full-fat and low-fat cheddar cheeses as related to type of fat mimetic. J. Food Sci. 62: 748-752.

Yasin, N. M. N. and S. M. Shalaby. 2013. Physiochemical and sensory properties of functional low-fat cheesecake manufactured using cottage cheese. Ann. Agri. Sci. 58: 61-67.

Pastorino, A. J., C. Hansen and D. J. McMahon. 2003. Effect of salt on structure function relationships of cheese. J. Dairy Sci. 86: 60-69.

Pereira, E. P., R. N. Cavalcanti, E. A. Esmerino, R. Silva, L. R. Guerreiro, R. L. Cunha, H. M. Bolini, M. A. Meireles, J. A. Faria and A. G. Cruz. 2016. Effect of incorporation of antioxidants on the chemical, rheological, and sensory properties of probiotic Petit Suisse Cheese. J. Dairy Sci. 99: 1762-1772.

Raphaelides, S., K. Antoniou, S. Vasilliadou, C. Georgaki and A. Gravanis. 2006. Ripening effects on the rheological behaviour of halloumi cheese. J. Food Eng. 76: 321-326.

Simoes, M. G., J. G. Rabelo, A. F. N. Domingues, E. B. Oliveira and C. L. F. Ferreira. 2013. Physicochemical properties of butter cheese from marajó manufactured with buffalo milk and cow milk. IOSR J. Environ. Sci. 9: 83-88.

Zheng, Y., Z. Liu and B. Mo. 2016. Texture profile analysis of sliced cheese about chemical composition and storage temperature. J. Chem. 2016: 8690380. 